\title{
A General Thermal Equilibrium Discharge Flow Model
}

\author{
Minfu Zhao, Dongxu Zhang and Yufeng Lv \\ Department of Reactor Engineering Technology, China Institute of Atomic Energy, Beijing 102413, China
}

Received: May 09, 2016 /Accepted: May 19, 2016 /Published: July 31, 2016.

\begin{abstract}
Based on isentropic flow and thermal equilibrium assumptions, a model was derived to calculate discharge flow rate, which unified the rules of room temperature water discharge, high temperature and high pressure water discharge, two-phase critical flow, saturated steam and superheated steam critical flow, and gave a method to calculate critical condition. Because of the influence of friction, the entropy is increased in the actual discharge process, and the discharge flow rate in thermal equilibrium condition can be obtained by the original model multiplied by an appropriate correction coefficient. The model calculated results agreed well with the experiment data of long nozzle critical flow.
\end{abstract}

Key words: Thermal equilibrium, critical flow, discharge flow rate.

\section{Nomenclature}

$\begin{array}{ll}C & \text { Empirical coefficient } \\ G & \text { Mass flow rate } \\ h_{0} & \text { Specific enthalpy at the nozzle inlet } \\ k & \text { Specific heat capacity ratio } \\ P_{0} & \text { Initial pressure } \\ P_{b} & \text { Back pressure } \\ P_{c r} & \text { Critical pressure } \\ S_{0} & \text { Specific entropy at the nozzle outlet } \\ V_{e} & \text { Velocity at the nozzle outlet } \\ \beta_{c r} & \text { Critical pressure ratio } \\ \rho & \text { Density }\end{array}$

\section{Subscript}

$\begin{array}{ll}0 & \text { the inlet condition } \\ b & \text { the outlet condition } \\ c r & \text { critical } \\ e & \text { equilibrium }\end{array}$

\section{Introduction}

When a vessel of pressurized fluid breaks, the fluid would blowdown to the environment drastically and a discharge flow occurs.

For room temperature water and any other incompressible fluid, the flow would not reach critical flow condition and the discharge flow rate depends on

Corresponding author: Minfu Zhao, associate professor, research fields: nuclear safety and thermal-hydraulics. the pressure difference of the nozzle inlet and the outlet, which can be calculated by the Bernoulli Equation [1], as

$$
G=\sqrt{2 \rho \cdot\left(P_{0}-P_{b}\right)}
$$

where, $G$ is mass flow rate, $\rho$ is water density, $P_{0}$ is initial pressure, $P_{b}$ is back pressure.

Due to the effect of friction and local resistance, the actual flow rate is lower than that calculated by Eq. (1). Therefore, an empirical coefficient is multiplied to Eq. (1), which becomes

$$
G=C \sqrt{2 \rho \cdot\left(P_{0}-P_{b}\right)}
$$

For the compressible fluid, such as perfect gas and superheated steam, a choking or critical condition would occur, where the flow rate no longer increases as the downstream pressure decreasing further to the critical pressure $P_{c r}$. According to the theories in aerodynamics [2], the critical pressure and critical flow rate can be evaluated by the following formulas (Eq. (3)):

$$
\begin{gathered}
P_{c r}=P_{0} \beta_{c r}=P_{0}\left(\frac{2}{k+1}\right)^{\frac{k}{k-1}} \\
G=\sqrt{k P_{0} \rho_{0}\left(\frac{2}{k+1}\right)^{\frac{k+1}{k-1}}}
\end{gathered}
$$


where, $P_{c r}$ is critical pressure, $\beta_{c r}$ is critical pressure ratio, $k$ is specific heat capacity ratio (specific heat capacity at constant pressure/specific heat capacity at constant volume), $\rho_{0}$ is the fluid density at the inlet of the nozzle. For the perfect gas, $k=1.4$; for the superheated steam, $k=1.3$, for the saturated water vapor, $k=1.135$. Considering the effect of friction and local resistance, an empirical coefficient should be applied to the original equation to obtain the actual flow rate, as following

$$
G=C \sqrt{k P_{0} \rho_{0}\left(\frac{2}{k+1}\right)^{\frac{k+1}{k-1}}}
$$

For high temperature and high pressure water or steam-water mixture, the phase change would occur during the discharge process, which eventually turns to steam-water mixture at lower pressure and temperature. The phase change makes the two-phase discharge flow pattern very complicated, which differs from room temperature water and water vapor, and the flow may reach critical condition or not [3]. Several tens of critical flow models have been proposed, but still there is no certain mathematical method $[4,5]$.

So far the current discharge flow theories base on different assumptions and the scope of application is relatively narrow. These explain why the two-phase critical flow models are quite different and can hardly be generally accepted. If a general model could be derived with few assumptions, but can be applied to the range from room temperature water to superheated steam, and further applying this model to two phase condition, then the problem to evaluate two-phase discharge flow would be solved radically.

Based on the above consideration, a general model has been proposed with isentropic flow and thermal equilibrium assumptions, which is applicable for both subcooled water and superheated vapor. Furthermore, considering the friction effect, a correction factor is introduced to the original model, thus the isentropic flow assumption is eliminated and the thermal equilibrium general model is obtained. The model estimated results agree well with the experiment data for long nozzles. The model also provides further insight into critical pressure.

\section{Model Derivation}

There are two assumptions: (1) The friction effect is ignored and the flow is considered isentropic; (2) The vapor phase and liquid phase are in thermal equilibrium, and the velocity is the same.

The mass flow rate at the nozzle outlet is defined as:

$$
G=\rho_{e} V_{e}
$$

where, $\rho_{e}$ is the fluid density at the nozzle outlet, $V_{e}$ is the velocity at the nozzle outlet. Because the friction effect is ignored, the outlet velocity can be obtained by energy conservation equation:

$$
V_{e}=\sqrt{2\left(h_{0}-h_{e}\right)}
$$

Substituting Eq. (7) to Eq. (6), the outlet mass flow rate can be obtained:

$$
G=\rho_{e} \sqrt{2\left(h_{0}-h_{e}\right)}=\rho\left(P_{e}, s_{0}\right) \sqrt{2\left(h_{0}-h\left(P_{e}, s_{0}\right)\right)}
$$

where, $h_{0}$ is the specific enthalpy at the nozzle inlet, $s_{0}$ is the specific entropy at the nozzle outlet, $h_{e}$ is the specific enthalpy at the nozzle outlet, $P_{e}$ is the nozzle outlet pressure.

For any certain inlet condition, the mass flow rate under different outlet pressures can be calculated by Eq. (8), among which the largest is the critical mass flow rate, and the corresponding outlet pressure is the critical pressure.

Eqs. (8) and (4) are totally consistent in principle, except that: during the derivation of Eq. (4), $\rho_{e}$ is calculated from the assumption that the relationship $P_{0}\left(\frac{1}{\rho_{0}}\right)^{k}=P_{e}\left(\frac{1}{\rho_{e}}\right)^{k}$ is satisfied during the isentropic process, then the perfect gas state equation is applied to calculate the outlet temperature, according to the inlet and outlet temperature difference and 
specific heat capacity, the enthalpy difference is obtained, therefore, Eq. (4) is only applicable to fluid of which state is close to perfect gas; while Eq. (8) completely adopts water and water vapor property equation for derivation, which is more close to real conditions and can be applied to any state. In other words, if we substitute the physical properties such as density, specific enthalpy to the perfect gas property in Eq. (8) and let $P_{e}=P_{c r}$, Eq. (8) becomes to Eq. (4).

For room temperature water, the density $\rho$ is almost constant, combining the definition of entropy, during the isentropic process, we can obtain:

$$
\begin{aligned}
& d s=\frac{d h}{T}-\frac{1}{\rho T} d P=0 \Rightarrow \\
& d h=\frac{1}{\rho} d P \Rightarrow h_{0}-h_{e}=\frac{P_{0}-P_{e}}{\rho}
\end{aligned}
$$

Thus, Eq. (8) may be simplified to Eq. (1):

$G=\rho_{e} \sqrt{2\left(h_{0}-h_{e}\right)}=\sqrt{2 \rho^{2}\left(\frac{P_{0}-P_{e}}{\rho}\right)}=\sqrt{2 \rho\left(P_{0}-P_{e}\right)}$

It can be concluded that Eq. (8) is a general model which is applicable to both subcooled water and superheated steam.

Taking the friction and local resistance effect into account, the actual discharge flow is not isentropic, referring to the approach used in Eqs. (2) and (5), by multiplying an empirical coefficient $C$, Eq. (8) becomes:

$$
G=C \rho\left(P_{e}, s_{0}\right) \sqrt{2\left(h_{0}-h\left(P_{e}, s_{0}\right)\right)}
$$

During the derivation of Eq. (9), only the thermal equilibrium assumption is applied, therefore, it is a general thermal equilibrium model.

\section{Model Prediction and Analysis}

\subsection{Discharge Flow Characteristics Analysis}

In this section, Eq. (8) is used to investigate the discharge flow phenomena and rules under different fluid state.

Set the initial pressure $P_{0}=10 \mathrm{MPa}$, for example, the variation of discharge mass flow rates with nozzle outlet pressure for different fluid state from the range of room temperature water $\left(20{ }^{\circ} \mathrm{C}\right)$ to superheated steam $\left(500{ }^{\circ} \mathrm{C}\right)$ are obtained, which are shown in Figs. $1-3$, respectively. Fig. 1 illustrates the subcooled water discharge condition, the temperature of which is $20^{\circ} \mathrm{C}$, $200{ }^{\circ} \mathrm{C}, 250{ }^{\circ} \mathrm{C}, 300^{\circ} \mathrm{C}$ and $310^{\circ} \mathrm{C}$, respectively; Fig. 2 shows the superheated steam discharge condition, the temperature of which is $315^{\circ} \mathrm{C}, 350^{\circ} \mathrm{C}, 400^{\circ} \mathrm{C}$ and 500 ${ }^{\circ} \mathrm{C}$, respectively; Fig. 3 shows the vapor and water mixture discharge condition, the thermal equilibrium quality is $0.02,0.04,0.06,0.08,0.1,0.2,0.3,0.4$ and 0.5 , respectively.

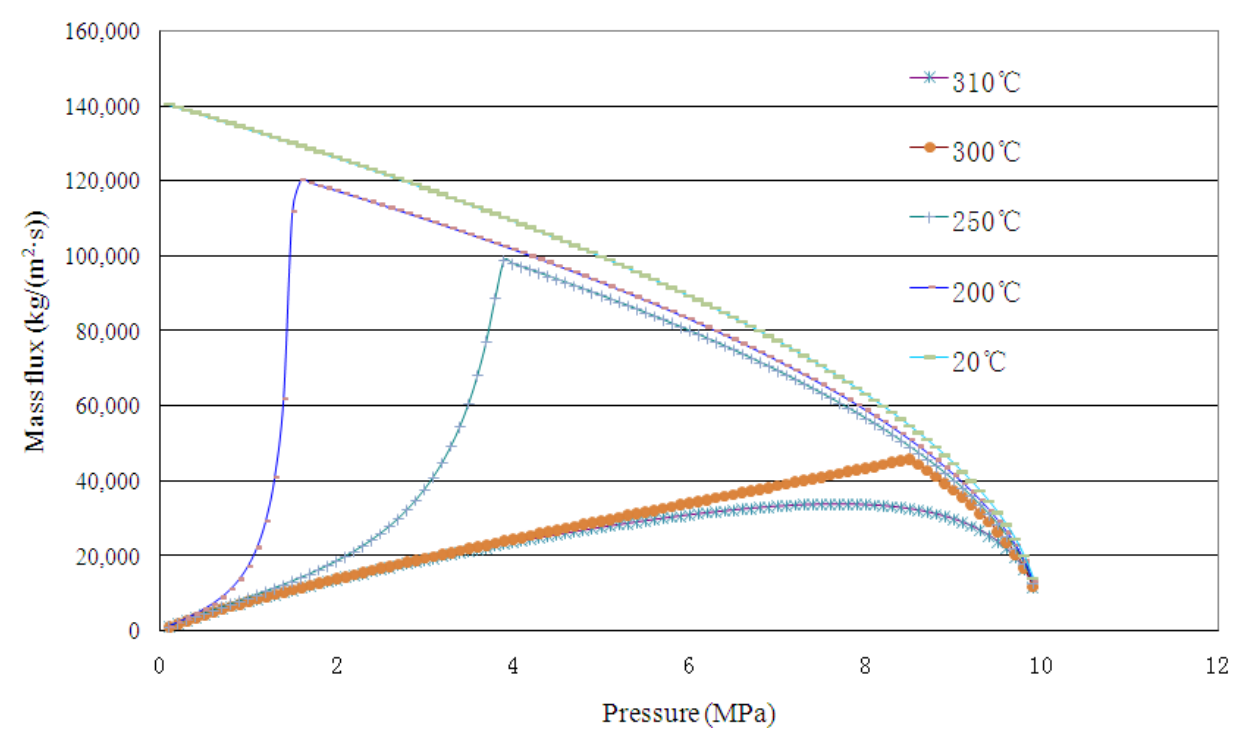

Fig. 1 Variation of mass flow rate with outlet pressure under subcooled conditions. 


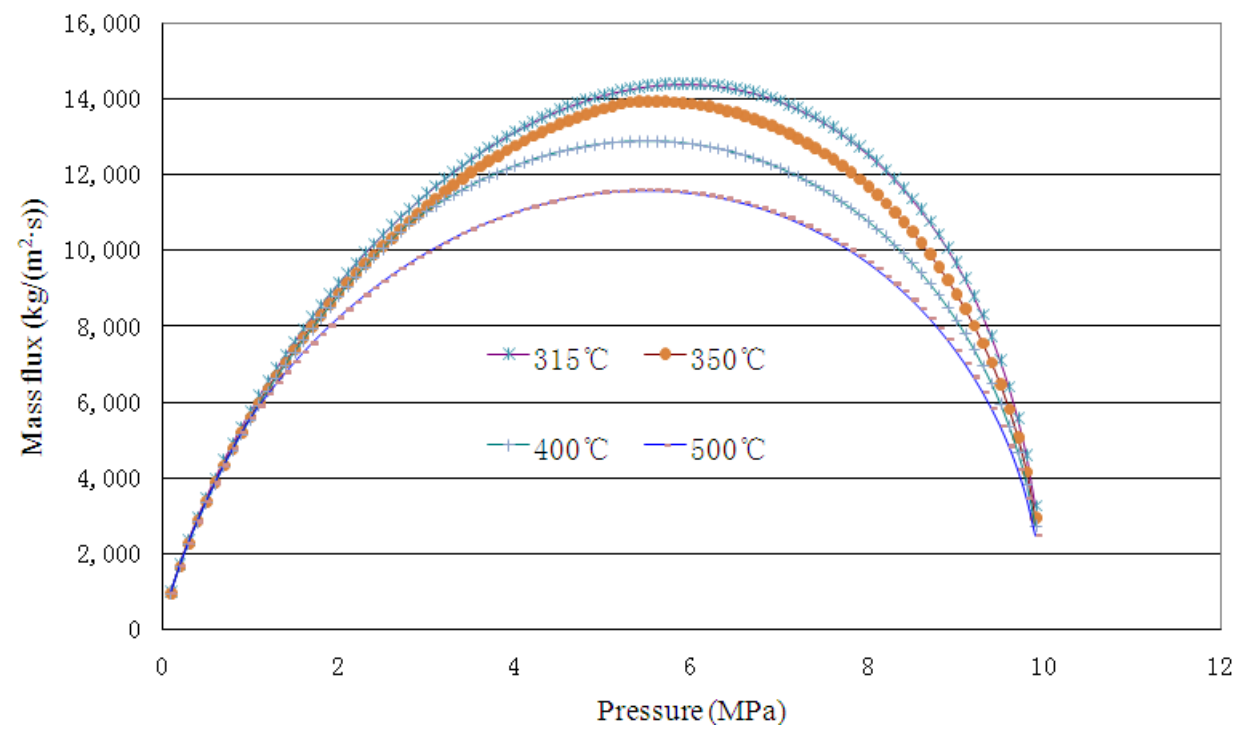

Fig. 2 Variation of mass flow rate on outlet pressure under superheated steam conditions.

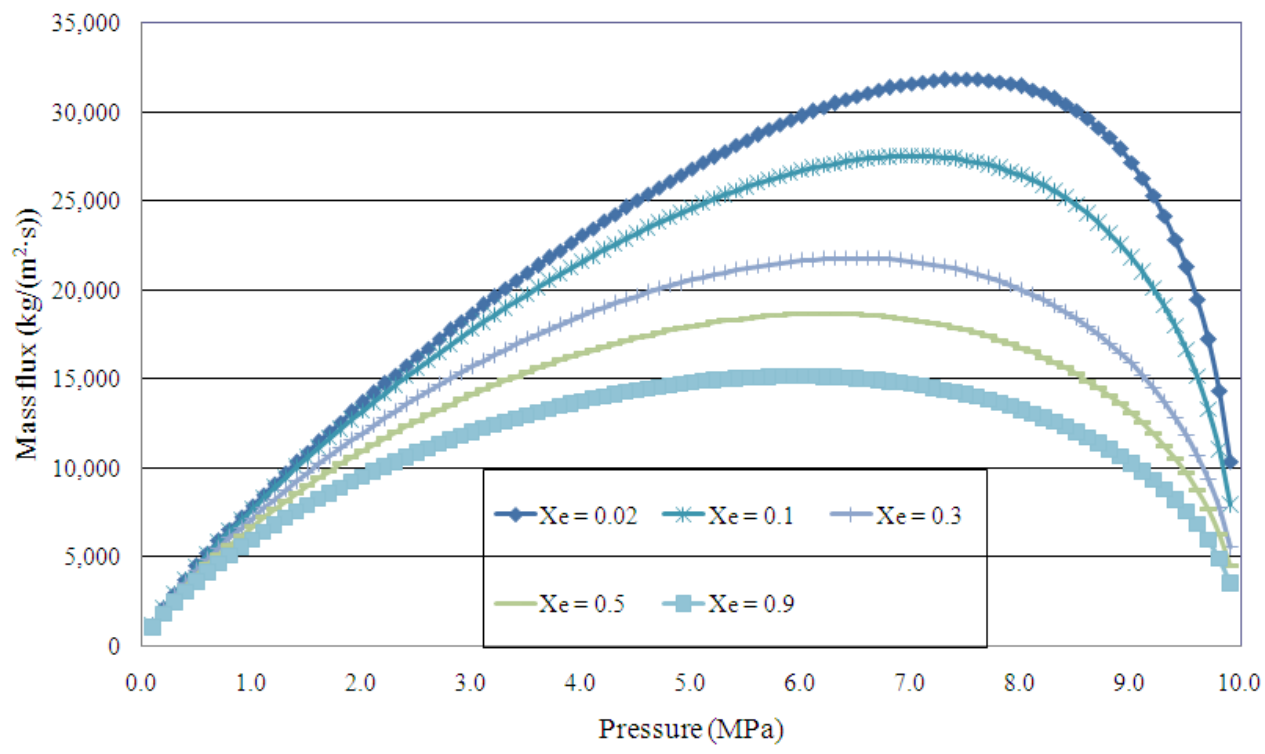

Fig. 3 Variation of mass flow rate on outlet pressure under saturated conditions.

It can be observed that, when the outlet pressure decreases gradually from $10 \mathrm{MPa}$, the mass flow rates of all conditions except room temperature water condition increase at first and then reach a maximum value, corresponding to a certain pressure, after which the mass flow rate decreases as the outlet pressure goes down.

Actually, when the back pressure is low enough, the outlet pressure would stay at a certain value which corresponds to the maximum mass flow rate, rather than decreasing to the back pressure, this phenomenon is called critical flow. Therefore, the maximum value of each curve is the critical mass flow rate for a certain pressure and temperature (or quality) and the corresponding outlet pressure is the critical pressure, the partial curve where outlet pressure is lower than the critical pressure is artificial and actually nonexistent.

It can also be concluded from the above figures that: for subcooled water, when the subcooling is large, as the temperature increases, the critical pressure increases and the critical mass flow rate decreases, it is found that the critical pressure is equal to the saturated pressure 
Table 1 Calculated critical pressure for initial pressure 10 MPa.

\begin{tabular}{llll}
\hline $\begin{array}{l}\text { Temperature } \\
\left({ }^{\circ} \mathrm{C}\right)\end{array}$ & Quality & $\begin{array}{l}\text { Critical } \\
\text { pressure } \\
(\mathrm{MPa})\end{array}$ & $\begin{array}{l}\text { Critical } \\
\text { pressure ratio }\end{array}$ \\
\hline 20 & -0.9977 & 0.10 & 0.01 \\
200 & -0.4189 & 1.60 & 0.16 \\
250 & -0.2445 & 3.90 & 0.39 \\
300 & -0.04916 & 8.50 & 0.85 \\
310 & -0.00463 & 7.70 & 0.77 \\
& 0.02 & 7.50 & 0.75 \\
& 0.10 & 7.00 & 0.70 \\
311 & 0.30 & 6.50 & 0.65 \\
& 0.50 & 6.20 & 0.62 \\
& 0.90 & 6.00 & 0.60 \\
315 & 1.020461 & 5.90 & 0.59 \\
350 & 1.150641 & 5.54 & 0.554 \\
400 & 1.282257 & 5.49 & 0.549 \\
500 & 1.493005 & 5.48 & 0.548 \\
\hline
\end{tabular}

corresponding to the initial temperature. When the temperature is close to the saturated temperature corresponding to the initial pressure, the critical pressure drops a little, deviates from the saturated pressure corresponding to the initial temperature. For superheated steam, the critical pressure for different temperature is almost constant, the critical flow rate decreases as the temperature increases because of the density change. For two phase mixture, as the thermal equilibrium quality increases, critical pressure decreases and critical mass flow rate decreases. Table 1 lists the critical pressure for different conditions.

When the initial pressure $P_{0}$ equals $13 \mathrm{MPa}$ and $16 \mathrm{MPa}$, respectively, the calculated discharge flow characteristic is similar with the condition that initial pressure $P_{0}=10 \mathrm{MPa}$.

\subsection{Model Validation}

To assess the accuracy of the general model, the results calculated by Eq. (8) and the experiment data [6] conducted for length to diameter 20, round-edge inlet nozzle are compared, which is shown in Figs. 4 and 5. It can be observed that the calculated mass flux (marked with cal.-1 in the figures) exhibits a similar trend with the experiment results in general, but the calculated mass flux is higher in quantitative. The reason is that the model is based on the isentropic flow assumption, but in reality, the effect of friction and form resistance is large and cannot be neglected.

If we calculate the mass flow rate using Eq. (9), and choose the empirical coefficient $C=0.82$ for subcooled condition and $C=0.9$ for the saturated condition, the newly calculated results (marked with cal.-2 in the figures) agree well with the experiment results, which is shown in Figs. 4 and 5. It could be concluded that the thermal equilibrium general model gives a good prediction of the critical mass flow rate in long nozzle.

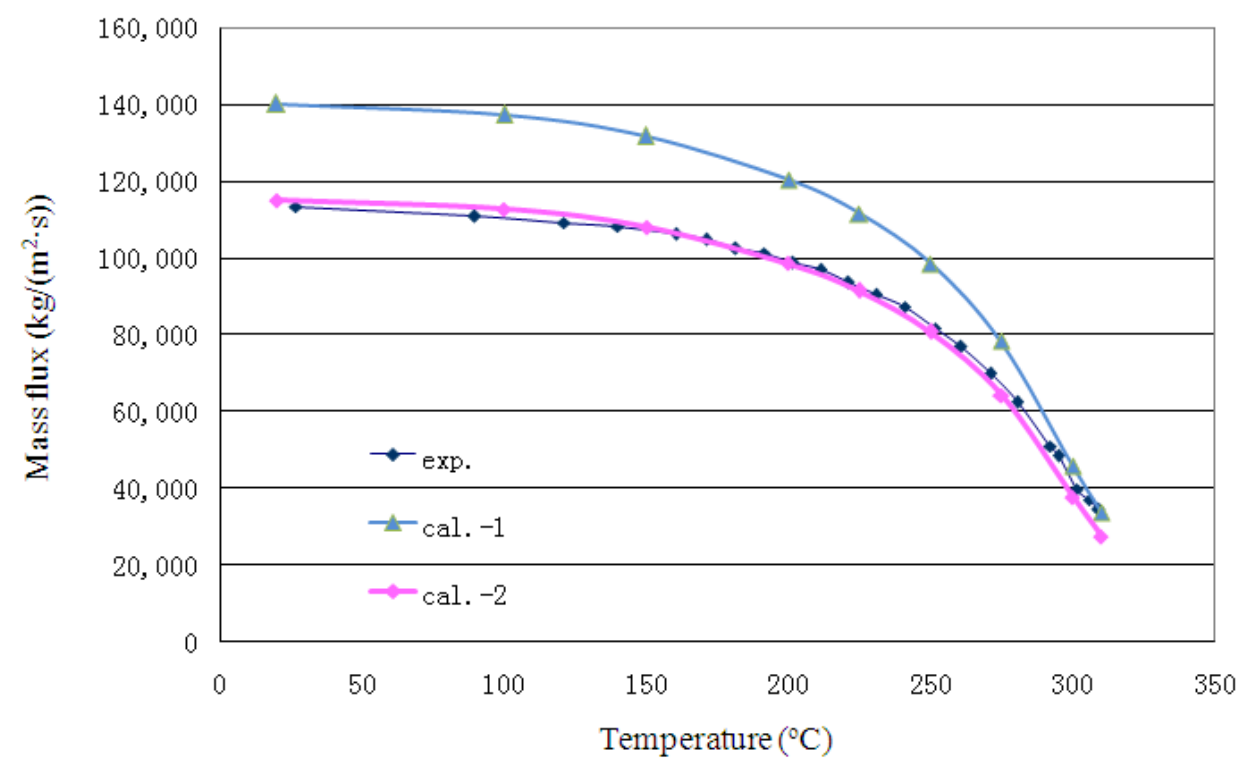

Fig. 4 Comparison of model prediction with experiment data under subcooled condition. 


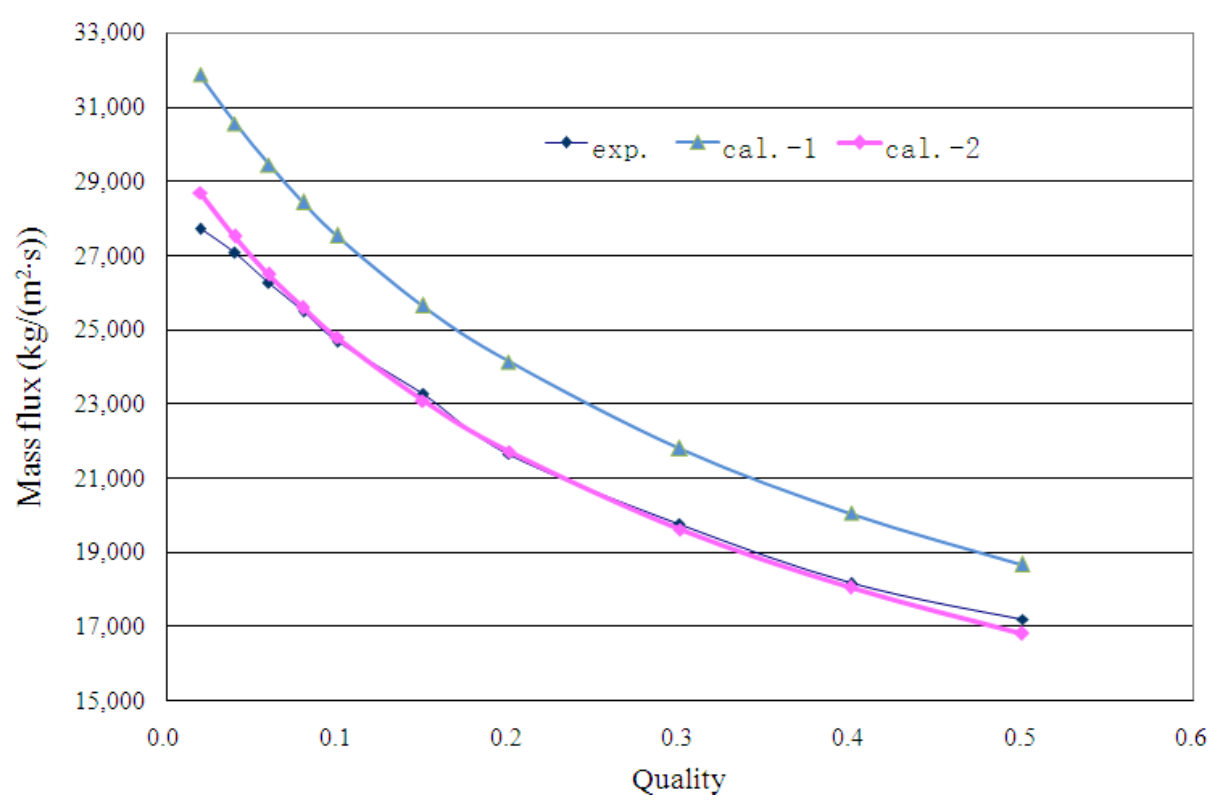

Fig. 5 Comparison of model prediction with experiment data under saturated condition.

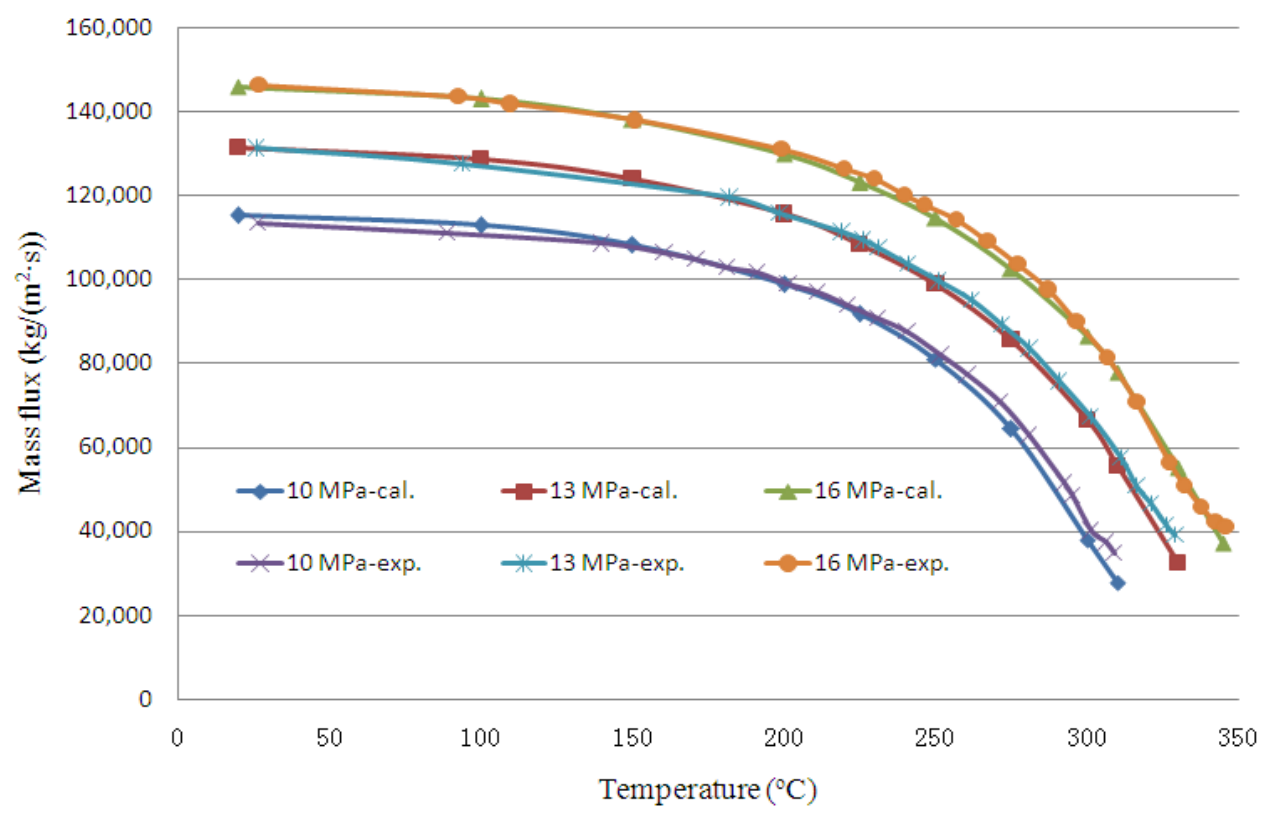

Fig. 6 Comparison of model prediction with experiment data under subcooled condition.

When the initial pressure $P_{0}$ equal to $13 \mathrm{MPa}$ and $16 \mathrm{MPa}$, respectively, the thermal equilibrium general model predicted results and long nozzle experiment results are in good agreement, which is shown in Figs. 6 and 7; And the value of empirical coefficient $C$ is the same with that of initial pressure $P_{0}=10 \mathrm{MPa}$.

\subsection{Determination of Empirical Coefficient C}

The empirical coefficient $C$ reflects the effect of friction and local resistance, therefore, it is related to the detailed structure of the nozzle. Furthermore, as discussed in Section 3.1, though the value of empirical coefficient $C$ is related to the fluid state, but whether under subcooled condition or saturated condition, $C$ is almost constant. Therefore, the CFD method could be applied to simulate room temperature water and superheated steam discharge $[7,8]$, respectively, thus the empirical coefficient $C$ is obtained. 


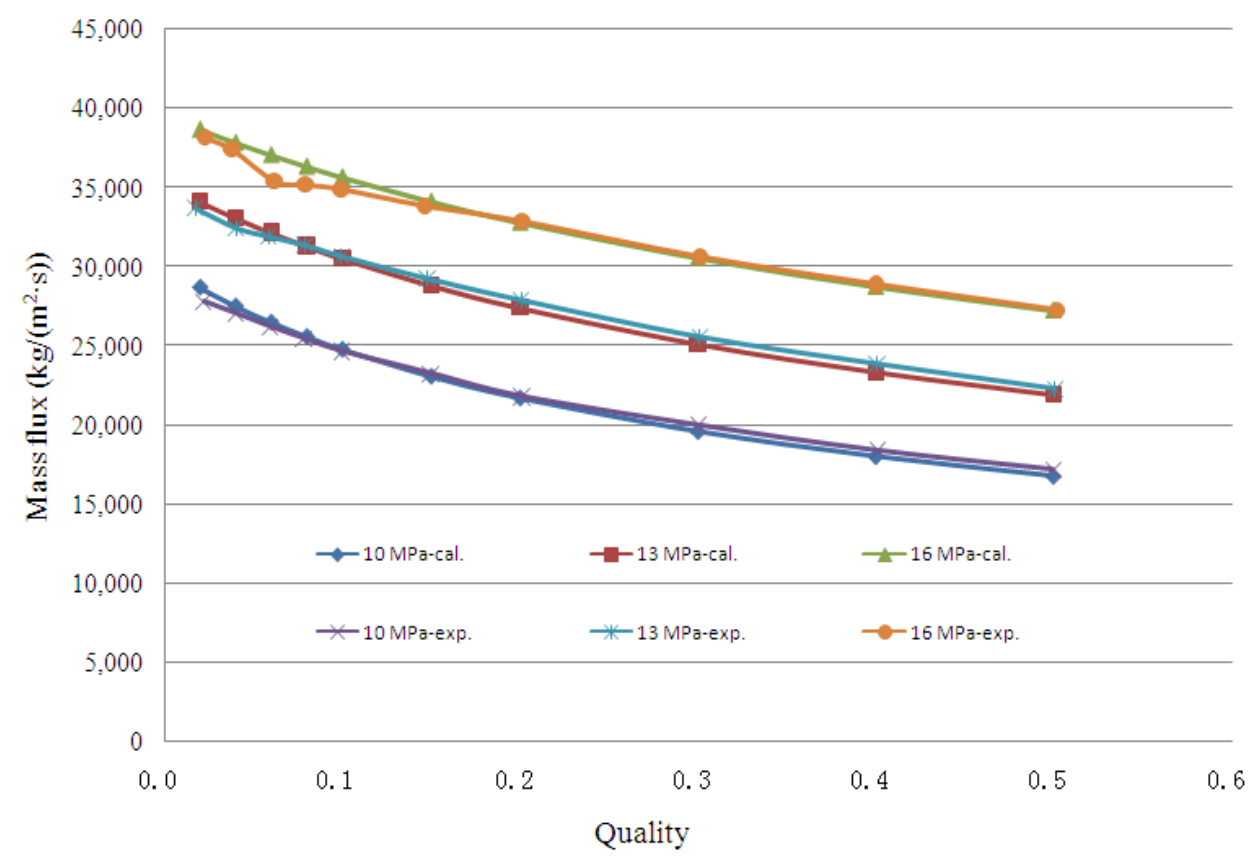

Fig. 7 Comparison of model prediction with experiment data under saturated condition.

Referring to the nozzle actual structure, the room temperature water discharge flow is simulated, and the computed empirical coefficient $C=0.84$; The discharge flow for superheated steam with temperature $500{ }^{\circ} \mathrm{C}$ is simulated, and the computed empirical coefficient $C=0.9$. It is found that simulated results are close to the experiment data, which indicate the CFD method is feasible to determine the empirical coefficient $C$.

\section{Conclusions}

(1) With the thermal equilibrium assumption, a general thermal equilibrium model was proposed. This model unified the flow rules of room temperature water discharge, high temperature and high pressure water discharge, two-phase critical flow, saturated steam and superheated steam critical flow, and could be applied to calculate critical pressure and critical mass flow rate.

(2) The model prediction results agreed well with the experiment data of long nozzle critical flow, illustrating that the model is accurate; the empirical coefficient $\mathrm{C}$ in the model can be obtained through the CFD simulation, and the availability of the model is thus enhanced.
(3) The model is only applicable to long nozzles, and thermal equilibrium condition, if a quantitative relational expression between thermal equilibrium degree and length to diameter ratio could be complemented, then all assumptions would be removed, and a more general discharge flow model would be obtained.

\section{Acknowledgments}

The present research was supported by the Large Advanced Pressurized Water Reactor National Science and Technology Key Project (2011ZX06004-024-07-09-00).

\section{References}

[1] Mo, N. 2000. Engineering Fluid Mechanics. Wuhan: Huazhong University of Science and Technology Press.

[2] Shen, D. W., Jiang, Z. M., and Tong, J. G. 2001. Engineering Thermodynamics. 3rd Edition. Beijing: Higher Education Press.

[3] Chen, Y. Z., Zhao, M. F., Yang, C. S., Bi, K. M., Du, K. W., and Zhang, S. M. 2012. "Research on Critical Flow of Water under Supercritical Pressures in Nozzles." Energy and Power Engineering 6 (2): 201-8.

[4] Levy, S., Abdollahian, D., Healzer, J., et al. 1982. Critical Flow Data Review and Analysis. Report for risk and safety management program. 
[5] Chen, Y. Z., Yang, C. S., Zhang, S. M., Zhao, M. F., Du, K. W., and Bi, K. M. 2009. "Evaluation of Existing Physical Models on Critical Flow Based on Experiment with a Nozzle." Atomic Energy Science and Technology 43 (6): 485-90.

[6] Chen, Y. Z., Zhao, M. F. et al. 2014. Experimental Study of Critical Flow at Steady State. Annual report of China institute of atomic energy.
[7] Aly, N. H., Karameldin, A., and Shamloul, M. M. 1999. "Modeling and Simulation of Steam Jet Ejector." Desalination 123 (1): 1-8.

[8] Pianthong K., Seehanam, W., Behnia, M., Sriveerakul, T., and Aphornratana, S. 2007. "Investigation and Improvement of Ejector Refrigeration System Using Computational Fluid Dynamics Technique.” Energy Conversion and Management 48 (9): 2556-64. 